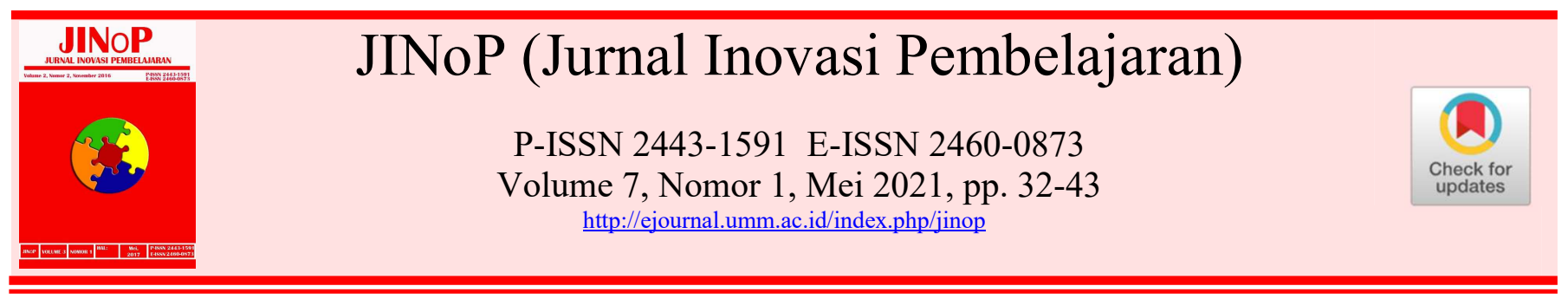

\title{
Analisis fungsi dan isi pantun masyarakat Desa Kopong dan relevansinya terhadap pembelajaran Bahasa Indonesia di SMP
}

\author{
Robertus Adi Sarjono Owon ${ }^{1)^{*}}$, Maria Ermelinda Dua Lering ${ }^{2)}$ \\ ${ }^{1}$ Pendidikan Bahasa dan Sastra Indonesia, Fakultas Ilmu Sosial dan Humaniora, IKIP \\ Muhammadiyah Maumere, Jalan Jend. Soedirman Waioti, Maumere Indonesia \\ ${ }^{2}$ Pendidikan Bahasa dan Sastra Indonesia, Fakultas Ilmu Sosial dan Humaniora, IKIP \\ Muhammadiyah Maumere, Jalan Jend. Soedirman Waioti, Maumere Indonesia \\ robertusadi99@gmail.com*; marlinlering85@gmail.com \\ *Penulis Koresponden
}

\begin{abstract}
ABSTRAK
Penelitian ini bertujuan untuk menganalisis fungsi dan isi pantun komunitas di Desa Kopong, Kecamatan Kewapante, Kabupaten Sikka. Di masa lalu, karya sastra lisan dipraktikkan di komunitas ini untuk mentransfer pesan. Penelitian ini menggunakan pendekatan kualitatif dengan metode deskriptif. Data yang didapatkan berupa pantun dan sajak dari keterlibatan dan observasi partisipan. Data dianalisis melalui teknik analisis isi dan validasi data dengan metode triangulasi. Hasil penelitian menunjukkan bahwa pantun masyarakat di Desa Kopong berfungsi sebagai sarana rekreasi, estetika, didaktik, moralitas, dan religius. Isi pantun antara lain penguatan nilai ketabahan, keuletan, kesopanan, kesukarelaan, dan agama. Temuan dari penelitian ini bermanfaat sebagai bahan ajar Bahasa Indonesia (BI) di Sekolah Menengah Pertama (SMP), khususnya terkait dengan kompetensi siswa dalam menganalisis bentuk dan isi puisi lama.

Kata Kunci: Bahasa Indonesia (BI); Fungsi; Isi; Pantun; Pembelajaran
\end{abstract}

\section{ABSTRACT}

This research aimed to analyze the function and content of community limerick in Desa Kopong, Kecamatan Kewapante, Kabupaten Sikka. Spoken literature works are largely practiced in this community to transfer messages among people. This research employed a qualitative approach with a descriptive method. The obtained data were in the form of rhymes and verses obtained from engagement techniques and participant observation. The obtained data were analyzed through content analysis techniques and data validation with triangulation methods. Results showed that the community limerick in Desa Kopong functions as a means of recreation, aesthetics, didactic, morality, and religion. The content of the limericks includes reinforcement of the values of grit, resilience, politeness, volunteerism, and religion. Finding from this research is significant for Bahasa Indonesia (BI) lesson in junior high schools (SMP), especially related to students' competency in analyzing the forms and contents of community limerick.

Keywords: Bahasa Indonesia (BI); Content; Function; Learning; Limerick

Diunggah: 2020-10-17; direvisi: 2021-01-15; diterima: 2021-04-23; dipublikasi: 2021-05-21

Copyright (c) 2020 Owon et al

This is an open access article under the $\mathrm{CC}-\mathrm{BY}$ license

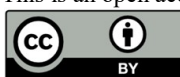

Cara sitasi: Owon, R. A. S., \& Lering, M. E. D. (2021). Analisis fungsi dan isi pantun masyarakat Desa Kopong dan relevansinya terhadap pembelajaran Bahasa Indonesia di SMP. JINoP (Jurnal Inovasi Pembelajaran), 7(1), 32-43. https://doi.org/10.22219/jinop.v7i1.14028

\section{PENDAHULUAN}

Pantun merupakan salah satu kekayaaan budaya bangsa dalam bentuk puisi lama. Pantun dijadikan sebagai alat penyampaian maksud dan tujuan secara tidak 
langsung. Selain itu, pantun dipakai sebagai sarana untuk mengungkapkan keadaan sesorang. Oleh karena itu, pantun identik dengan pengguna atau penyampai pesan tersebut, bahkan mewakili wujud warga masyarakat pemakai pantun tersebut. Pada masa lampau, pantun adalah bentuk sastra yang disampaikan secara turun temurun dari orang tua kepada generasi berikutnya yang dipakai oleh masyarakat dalam berbagai hal. Dewasa ini pantun telah banyak dibukukan sebagai buah karya tulis. Asnawi (2017) dan Yuliansyah (2019) mengungkapkan bahwa pantun adalah aset budaya masyarakat yang sangat berharga nilainya karena pantun memuat berbagai bentuk nilai kearifan lokal masyarakat penggunanya.

Sebagai sastra lisan, pantun memiliki tempat tersendiri di hati masyarakat. Sastra yang dilisankan muncul dan bertumbuh di tengah komunitas jauh sebelum sastra yang dibukukan. Kini, sastra lisan tergeser oleh kemajuan teknologi dan ilmu pengetahuan. Perlu disadari bahwa sastra lisan adalah kekayaan budaya bangsa sebagai warisan leluhur dengan nilai-nilai yang berhubungan dengan kehidupan masyarakat dewasa ini (Owon, 2017; Owon \& Nanda Saputra, 2021; Widyanti, 2016)

Terlebih lagi, pantun dapat dikatakan sebagai alat pemelihara kelestarian budaya dalam wujud bahasa (Apriansa, n.d.; Hasim, 2007; Multafifin, 2015, 2018; Aryanto \& Rakhmat, 2014; Wiediharto et al., 2020) Pantun berguna sebagai sarana untuk menjaga keaslian suatu bahasa. Jadi, tidak berlebihan jika pantun dinyatakan sebagai bagian yang penting di dalam komunitas masyakarat karena rasa, nilai, kearifan, pesan, dan perannya sebagai sarana renungan untuk menapaki kehidupan yang mendatangkan khayalan sekaligus himpunan kisah hidup manusia dari banyak matra yang meliputi ranah jasmani dan rohani. Pantun juga melahirkan nilai estetis bagi manusia yang menciptakan pengalaman batin yang sangat indah dengan sarat makna. Lagi pula, pantun melahirkan arti kearifan yang pekat, bening, dan masuk ke hati sebagai bahan refleksi dalam merajut jalan hidup selanjutnya. Dengan demikian, pantun yang lahir dari masyarakat tradisional perlu diajarkan di lingkup pendidikan formal.

Kenyataannya, pantun memang menjadi salah satu teks kajian dalam pembelajaran Bahasa Indonesia (BI). Akan tetapi, bahan ajar yang disediakan adalah pantun yang sudah dibukukan. Pendidik mentransfer pantun-pantun dari buku teks kepada peserta didik dengan cara melengkapi pantun rumpang, menulis pantun sesuai tema, dan berbalas pantun. Padahal, pendidik sebenarnya dapat memulai pembelajaran pantun dari kearifan lokal yang ada di daerahnya dengan menelaah nilai dan pesan moral yang terkandung di dalam pantun tersebut.

Pantun dalam masyarakat tradisional mewakili nilai-nilai masyarakat yang diwujudkan dalam bentuk acuan tingkah laku (Sari, 2021; Munir, 2020) Pantun biasanya disampaikan secara estafet dari orang yang lebih tua kepada orang yang lebih muda. Pantun merupakan produk transmisi dari generasi ke generasi, biasanya dipindahkan melalui bahasa lisan atau tulis, bahkan juga dengan upacara-upacara, yang berisi ide-ide, perasaan-perasaan, dan nilai-nilai yang dihubungkan dengan kehidupan kelompok sosial (Malaon, 1986). Di dalamnya termuat berbagai nilai-nilai yang dapat dipedomani sebagai pedoman bagi masyarakat dalam bertingkah laku yang melahirkan tradisi dan kebudayaan yang merupakan bagian dari foklor. Dengan demikian, kebudayaan dipandang sebagai hasil karya manusia yang tumbuh subur seirama perkembangan peradabannya (Sartini, 2009). 
Di Desa Kopong, sebagian besar masyarakat bermata pencaharian sebagai petani. Bahasa sehari-hari dalam berkomunikasi adalah bahasa Sikka Krowe yang dominan digunakan oleh masyarakat Kabupaten Sikka dalam berkomunikasi. Sistem lambang bunyi yang arbriter ini dijadikan sebagai bahasa kebudayaan masyarakat Desa Kopong. Sebagai bahasa kebudayaan lumrah jika bahasa Sikka digunakan dalam berbagai tradisi kebudayaan seperti pantun dan syair (kleteng latar).

Berdasarkan hal tersebut, perlu dilakukan penelitian terhadap pantun masyarakat Desa Kopong sebagai penguat nilai identitas pemuda Kabupaten Sikka. Ditilik dari isinya, pantun dibedakan menurut kelompok usia yakni kelompok anak-anak (jenaka dan teka teki), golongan orang muda (percintaan), dan orang tua (nasihat) (Hasim, 2007; Wiguna et al., 2017) Hal tersebut juga ditemukan pada masyarakat Desa Kopong. Penelitian ini difokuskan pada fungsi, isi, dan makna pantun yang terdapat di wilayah tersebut. Penelitian ini diharapkan dapat memiliki manfaat terhadap dunia pendidikan, pembinaan, dan pengembangan bahasa daerah.

Hasil penelitian diharapkan dapat berguna baik secara keilmuan, yakni sebagai dokumentasi bahasa Sikka sebagai strategi mencegah kepunahan bahasa Sikka, maupun sebagai upaya perwujudan pembinaan dan pengembangan bahasa Sikka. Secara implementatif, penelitian ini diharapkan dapat berfaedah bagi peneliti berikutnya sebagai referensi sandingan yang akan melakukan penelitian tentang bahasa Sikka dalam aspek objek kajian dari perspektif lain. Penelitian ini juga diharapkan dapat bermanfaat terhadap dunia pendidikan sebagai sebuah alternatif dalam pengembangan bahan ajar Bahasa dan Sastra Indonesia di sekolah menengah.

\section{METODE}

Penelitian ini bermaksud mengidentifikasi isi dan fungsi pantun melalui pendekatan kualitatif. Fakta-fakta kebahasaan dan kesastraan sebagai bentuk data kebahasaan dan kesastraan sengaja ditemukan untuk mendapatkan makna yang utuh. Metode yang dipakai dalam pembahasan adalah deskriptif kualitatif.

Penelitian ini dilakukan di Desa Kopong, Kecamatan Kewapante, Kabupaten Sikka, Nusa Tenggara Timur. Data penelitian ini berupa baris dan bait pantun masyarakat Desa Kopong. Sumber data penelitian ini adalah informan yang kriterianya ditetapkan berdasarkan kriteria informan kebahasaan yakni yang memenuhi persyaratan sebagai tokoh yang dituakan dalam masyarakat (usia di atas 50 tahun), menguasai seluk-beluk puisi lama, menguasai bahasa daerah setempat, dan memiliki waktu yang cukup (Mahsun, 2007; Martha, E., \& Kresno, 2016). Pengumpulan data dilakukan dengan teknik simak-cakap dan pengamatan partisipatif yang digunakan untuk mengumpulkan data melalui apa yang ditangkap oleh pancaindera yakni peneliti sungguh-sungguh ada bersama narasumber (Arikunto, 2007; Rahmat, 2009; Sudaryanto, 1993). Validasi data dilakukan dengan triangulasi di mana beberapa teknik pengumpulan data dipakai untuk saling melengkapi (Miles \& Huberman, 1992) karena setiap metode pengumpulan data memiliki kelemahannya masing-masing (Cohen et al., 2016; Moleong, 2008). Hal ini dilakukan dengan mengobservasi pesan teks berdasarkan indera dengar, indera rasa, dan indera lihat (Eriyanto, 2011; Mahsun, 2007). 


\section{HASIL DAN PEMBAHASAN}

Analisis data dilakukan dengan teknik analisis isi. Hasil penelitian menunjukkan bahwa pantun masyarakat Desa Kopong dapat memperkuat identitas pemakainya. Identitas masyarakat desa dapat diperkuat dengan adanya nilai kesopanan, religius, ketabahan, sukarelawan, dan keuletan.

Berkaitan dengan fungsi karya sastra, pantun masyarakat Desa Kopong memiliki fungsi sebagai 1) pemberi hiburan bagi pendengar atau pembacanya (rekreatif); 2) ajaran atau didikan yang dapat mengarahkan menanamkan nilai-nilai kebenaran dan kebaikan (didaktif); 3) pemberi keindahan untuk penikmat/ pembacanya (estetis); 4 pencerhan untuk mengetahui hal yang baik dan buruk (moralitas); dan 5) alat untuk mendekatkan manusia dengan pencipta-Nya (religius) yang dijelaskan sebagai berikut.

\section{Fungsi Pantun Masyarakat Desa Kopong}

a) Fungsi rekreatif

Fungsi ini sering dijumpai dalam suasana santai antara sekelompok pemuda dan pemudi. Pada saat pesta pertunangan atau pernikahan, kaum remaja Desa Kopong biasanya menghabiskan malam dengan berbalas pantun dengan tujuan untuk saling bersenda gurau, mencari kekasih, dan mempererat tali silahturami. Pantun-pantun yang biasa diucapkan tergambar berikut ini (Gambar 1):

\begin{tabular}{|ll|}
\hline Hai ata met ia & Anak gadis siapakah gerangan \\
Beset ganu mu'u merak & Cantik dan montok bagai pisang merah \\
Soba 'raintan naran & Andai kutahu gerangan namanya \\
Topo nurak in da'a mate & Ku panggil "Nurak" sampai mati \\
& \\
Balasan pantun: & \\
Mude tawa ripa napun puhe & Jeruk tumbuh di pinggir kali \\
Tawa nora golo wuan lamak & Tumbuh langsung berbuah pula \\
Mo'a aman Au lopa buhe & Saudaraku jangan kau tipu \\
Odi ganu te besi sa rak & Semangatmu kan seumur bunga labu \\
& \\
\hline
\end{tabular}

\section{Gambar 1. Fungsi rekreatif}

Kaum muda saling mengolok dan saling berjanji akan mengenang hingga maut memisahkan. Sebaliknya, pemudi menekankan bahwa kesombongan itu hanya akan seperti bunga labu yang mekarnya cuma sebentar dan tidak bertahan lama.

\section{b) Fungsi didaktik}

Masyarakat Desa Kopong menggunakan sarana pantun untuk mengajar dan mendidik anak-anak. Hal ini dilakukan oleh orang tua pada malam menjelang tidur. Orang tua biasa mendongeng dan di dalam dongeng tersebut disisipi dengan pantun. Bagi mereka, pantun sangat efektif dalam menurunkan nilai-nilai kehidupan karena pesannya samar dan penyampaiannya santun.

Hal ini tergambar pada bait pantun berikut (Gambar 2): 


\begin{tabular}{|ll|}
\hline Ular wa lolo herin & Ada ular berlalu di pinggiran \\
Lolo da'a natar mapat & Merayap sampai ujung kampung \\
U'at naha du duku doeng & Bekerja harus tekun dan telaten \\
Tenat naha di bli magit & Bekerja hingga tujuan tercapai \\
& \\
Dala gete ripa main & Bintang Kejora terbit di timur \\
Ple'ak da'a tipang sina & Memancar sampai ke jendela \\
'Au tibo la'en ata lamen & Wahai kau sang muda belia \\
Naha modung mior tajong maor & Karaktermu mulia dan terpuji \\
\hline
\end{tabular}

\section{Gambar 2. Fungsi didaktik}

Pada bait-bait pantun tersebut diisyaratkan agar masyarakat Desa Kopong senantiasa bekerja keras dan memiliki komitmen yang tinggi dalam mencapai citacita. Bait selanjutnya mengajarkan orang muda untuk selalu memperlihatkan karakter yang baik dalam kehidupan bersama. Dengan berkarakter terpuji, sebagian cita-cita diyakini sudah tercapai.

\section{c) Fungsi estetis}

Bagi masyarakat Desa Kopong, hidup adalah seni. Seni bertutur kata, seni bekerja, seni bergaul, dan sebagainya.

Hal ini tercermin pada bait-bait pantun berikut (Gambar 3):

\begin{tabular}{|ll|}
\hline Nale napun blau apun & Melewati kali takut embun \\
Nale wolo blau dara & Melewati bukit takut panas \\
Naruk tutur naha bepi & Berbicara mesti santun \\
Naruk harang naha plolo & Berkata harus seiring perbuatan \\
& \\
Ipun ketik wali nanga & Ikan kecil di mulut muara \\
Lolo reta namang loran & Berenang lincah sampai ke darat \\
Imung deung dopo dete & Sahabat dan teman sangatlah indah \\
Leta let masik kurang duna & Susah senang selalu bersama \\
& \\
Bedi bing ripa wolo & Senjata berbunyi di balik bukit \\
Negur daa okang loran & Suaranya terdengar di tengah kampung \\
Bête perun kelan kirek & Ciptakan motif yang elok rupawan \\
Sareng weli naran aman & Demi memuliakan saudara tersayang \\
& \\
\hline
\end{tabular}

\section{Gambar 3. Fungsi estetis}

Bait I pantun tersebut menggambarkan bahwa dalam bertutur bahasa, harus seiring sejalan antara perkataan dan perbuatan. Dengan demikian, orang akan selalu terkenang dan mempercayai setiap perkataannya. Bait II pantun tersebut melukiskan bahwa dalam persahabatan harus selalu dipelihara perasaan senasib dan sepenanggungan. Dengan begitu, apa pun yang dalami dan dirasakan seorang sahabat, pasti dirasakan pula oleh yang lainnya. Hal ini dapat menciptakan suasana keindahan batin yang tiada terkira. Selanjutnya bait III mengandung pesan bahwa seorang pemudi harus membuat kain tenun dengan motif yang menarik untuk dipersembahkan kepada saudaranya. 


\section{d) Fungsi moralitas}

Masyarakat Desa Kopong pun menggunakan pantun sebagai wahana pembentukan moralitas. Semua petunjuk dan larangan yang berlaku di tengah masyarakat dipesankan melalui pantun.

Hal ini dapat terlihat pada bait pantun berikut (Gambar 4):

\begin{tabular}{|ll|}
\hline Tili kikik kiring narang & Burung berkicau membawa kabar \\
Narang lau ata niang & Kabar dari perantauan \\
Uru piren tada glaran & Tanda larang telah dipasang \\
Tena jaga agang niang tana & Untuk memelihara keutuhan kampung \\
& \\
Labu werun wali peti & Baju baru di dalam peti \\
Peti mitan jaga gahu & Peti hitam selalu dijaga \\
Lopa gou lori ata duen & Jangan melewati batas kebun orang \\
Odi duen bano gogo pagong & Nanti bencana datang menghadang \\
\hline
\end{tabular}

\section{Gambar 4. Fungsi moralitas}

Kedua bait pantun tersebut mengajarkan hal baik dan tidak baik jika dilanggar oleh masyarakat. Bait I berisi peringatan bahwa ada tanda-tanda khusus sebagai pembatas wilayah yang tidak boleh dilanggar agar keutuhan wilayah tetap terjaga. Bait II berisi tentang larangan untuk tidak mengambil milik orang lain. Jika hal tersebut terjadi, orang tersebut akan mendapat malapetaka seumur hidupnya.

\section{e) Fungsi religius}

Fungsi ini berkaitan dengan kepercayaan masyarakat terhadap sang Pencipta langit dan bumi, Tuhan yang mahakuasa. Pantun ini disampaikan untuk mengajak masyarakat agar taat beribadah dan setia menjalankan ajaran agama yang dianutnya.

Hal ini terbaca pada bait pantun berikut (Gambar 5):

\begin{tabular}{|ll|}
\hline Kedur Aun memun merak & Kakatua berparuh merah \\
Due reta koja wutun & Hinggap di atas pucuk kenari \\
Neni mora ina niang tanah wawa & Mintalah pada Tuhanmu penjaga bumi \\
Hawong mora ama lero wulang reta & Mohonlah pada Allahmu penguasa langit \\
\hline
\end{tabular}

\section{Gambar 5. Fungsi religius}

Bait pantun ini mengandung pesan kepada masyarakat untuk selalu bersandar pada kehendak Tuhan dan selalu berkanjang dalam doa. Masyarakat hendaknya menyerahkan hidupnya pada penyelenggaraan Tuhan saja.

\section{Isi Pantun Masyarakat Desa Kopong}

\section{a) Pantun Masyarakat Desa Kopong sebagai penguat nilai kesopanan}

Masyarakat Desa Kopong diharapkan memilki keramahan terhadap seseorang. Bukan hanya kepada orang tua, melainkan sebaya, atau anak-anak.

Nilai keramahan tersebut dapat terlihat pada pantun berikut (Gambar 6): 


\begin{tabular}{|ll|}
\hline Meti api mope apa & Bawa api bakar apa \\
Ikot ba'a mole holo & Atur kayu lalu nyalakan \\
Lamen hai met ia & Wahai pemuda siapakah dia \\
Nari wa'in holo bako & Singgah sebentar sekedar merokok \\
\hline
\end{tabular}

\section{Gambar 6. Nilai kesopanan}

Sebait pantun tersebut diucapkan oleh seorang gadis kepada seorang pemuda yang kebetulan baru dilihatnya melintas di depan rumah. Sebagai bentuk keramahannya, ia mengundang si Pemuda untuk beristirahat sambil mengisap rokok.

\section{b) Pantun Masyarakat Desa Kopong sebagai penguat nilai religius}

Sebagai masyarakat desa yang masih terikat budaya, masuknya ajaran agama diterima dengan senang hati. Ajaran agama Kristiani menjadi pedoman masyarakat Desa Kopong dalam membangun kebersamaan dan relasi dengan Tuhan dan alam ciptaan. Tradisi yang diwariskan turun temurun adalah kebiasaan saling ajak melakukan devosi kepada Bunda Maria.

Hal ini tercermin pada bait pantun berikut (Gambar 7):

\begin{tabular}{|ll|}
\hline Manu lau koko kiring & Ayam jantan sudah berkokok \\
Koko baa hagong walong & Berkokok tanda memanggil pula \\
Mai diri Inan kiring & Mari simak nasihat Bunda \\
Mai rena inan donen & Mari dengarkan petunjuk Bunda \\
\hline
\end{tabular}

\section{Gambar 7. Nilai religius}

Pantun ini biasa dituturkan oleh pengurus komunitas basis gerejani (KBG) untuk seluruh anggotanya agar segera mendaraskan do'a Rosario kepada Bunda Maria, Bunda Yesus Sang Juru Selamat.Kebiasaan ini sering diadakan pada bulan Mei dan Oktober setiap tahun.

\section{c) Pantun Masyarakat Desa Kopong sebagai penguat nilai ketabahan}

Masyarakat Desa Kopong pada umumnya bermata pencaharian sebagai petani. Profesi ini menuntut adanya kesabaran dalam mengerjakannya. Para petani tidak bisa langsung memanen hasil pertaniannya dalam waktu yang singkat. Untuk itu, diperlukan kesabaran dalam menanti tanaman memberikan hasil.

Hal ini tergambar dalam bait pantun berikut (Gambar 8):

Pau nurak niluk klikuk

Ilur mo teto redong

Wui leron nawang wulan

Ihit rua witi dolot hutu tedang
Mangga mengkal asam rasanya

Air liur meleleh tiada henti

Tunggu hari bahkan bulan berganti

Menanti panen berlimpah-limpah

\section{Gambar 8. Nilai ketabahan}


Pantun ini biasanya disampaikan oleh kepala kampung kepada semua warga untuk selalu berkanjang dalam menunggu musim panen. Kesabaran akan mendatangkan hasil panen yang berlimpah.

\section{d) Pantun Masyarakat Desa Kopong sebagai penguat nilai kesukarelawanan}

Salah satu karakter masyarakat Desa Kopong dan desa-desa pada umumnya adalah mengutamakan solidaritas dalam semangat kekeluargaan. Masyarakat dituntut saling bantu dalam suka maupun duka. Warga yang lemah ditopang oleh warga yang kuat dan warga yang miskin dipenuhi kebutuhannya oleh yang kaya. Setiap orang menampakkan wajah kesukarelawanan meskipun ia terlihat miskin.

Hal ini terbersit pada bait pantun berikut (Gambar 9):

\begin{tabular}{|ll|}
\hline Mu'u susu ubun buluk & Pisang susu pucuknya pendek \\
Tawa wawa dan blatan & Tumbuh di bawah tangga yang sejuk \\
Mai ita ibo mole abo & Mari kita saling membantu \\
Dodor ho'or tena sudan sogor & Membimbing hingga dia mandiri \\
& \\
Tili kikik kiring inang & Burung berkutut berkicau riang \\
Rawa gakar hagong amang & Burung balam membawa kabar \\
Ita moret naha lakang wi'it & Kita yang hidup harus saling menolong \\
Loning ita ele Sikka ata iwat & Karena kita bukanlah orang lain \\
\hline
\end{tabular}

\section{Gambar 9. Nilai kesukarelawanan}

Kedua bait pantun tersebut mengisyaratkan masyarakat Desa Kopong yang dermawan. Mereka saling menolong dan menopang dalam hidup karena mereka adalah satu komunitas yang seasal-usul. Pantun ini biasa diungkapkan oleh para orang tua sebagai petuah kepada kaum keluarga dan anak-anaknya.

\section{e) Pantun Masyarakat Desa Kopong sebagai penguat nilai keuletan}

Di samping menjadi petani, sebagian warga masyarakat Desa Kopong pun suka merantau. Para perantau itu biasanya meninggalkan desanya untuk jangka waktu puluhan tahun. Tujuannya adalah memperbaiki taraf hidup karena dengan merantau atau mencari nafkah di negeri orang, mereka dapat membangun rumah yang layak huni. Sebagai seorang perantau, dituntut adanya keuletan dalam bekerja demi mengumpulkan banyak uang dan barang.

Hal ini tercermin dalam bait pantun berikut (Gambar 10):

\begin{tabular}{|ll|}
\hline Koja reta napun Luruk & Pohon kenari di kali Luruk \\
Rawa ga koe ra'ong & Burung balam makan berkali-kali \\
Masik aning borok bata gete & Meski badai datang menghadang \\
Tuku naha saing genang & Tetap berlayar hingga sampai tujuan \\
\hline
\end{tabular}

\section{Gambar 10. Nilai keuletan}

Pantun tersebut menandakan bahwa masyarakat Desa Kopong selalu pantang menyerah dalam menghadapi berbagai tantangan dan cobaan hidup. Tantangan itu tidak boleh menyurutkan langkah, melainkan harus tetap fokus pada pencapaian tujuan. 
Ditinjau dari hasil pembahasan yang menelaah tentang fungsi dan isi pantun masyarakat Desa Kopong, dapat ditarik benang merah dalam hubungannya dengan pembelajaran di kelas. Salah kompetensi dasar yang menjadi bahan kajian pada Peraturan Menteri Pendidikan dan Kebudayaan Nomor 21 tahun 2016 mengenai standar isi, berkaitan dengan teks puisi rakyat; pantun. Pantun merupakan puisi lama Indonesia yang berkembang dan hidup di tengah masyarakat Indonesia. Hal ini sejalan dengan (Primasari et al., 2016; Sari, 2021) yang menekankan bahwa kriteria kelayakan bahan ajar, yakni: sesuai dengan kemampuan siswa, kepribadian dan budaya Indonesia, intelektualitas peserta didik, aktual, dan keluasan bahan ajar, dapat dibaca dengan baik, bermanfaat dan selaras dengan tujuan pembelajaran sastra.

Untuk itu, materi terkait teks pantun bersumber dari kearifan lokal masyarakat Desa Kopong dapat diterapkan dalam pembelajaran di kelas. Mengingat pantun masyarakat Desa Kopong dan daerah lainnya di Indonesia dekat dengan kehidupan peserta didik, sebaiknya diawali secara kontekstual seirama dengan (Nurhadi, 2004) yang mengatakan bahwa pendekatan pembelajaran berdasarkan konteks (CTL) adalah konsep pembelajaran yang berusaha mensinergikan bahan pembelajaran dengan konteks nyata dan memotivasi siswa menciptakan relasi antara apa yang dipelajarinya dengan fakta dalam kehidupan.

\section{Fungsi pantun dalam pembelajara}

Pembelajaran teks pantun dengan pendekatan kontekstual dapat mengikuti sintak sebagai berikut:

\section{1) Orientasi}

Pada tahap ini, pendidik melantunkan pantun atau memutarkan video warga setempat yang sedang berpantun. Pantun yang dipilih hendaknya mengandung nilai kesopanan, moralitas, dan keuletan. Pendidik perlu selektif dalam memilih pantun yang dijadikan sebagai bahan ajar dengan memperhatikan usia peserta didik. Selanjutnya, peserta didik menuliskan larik demi larik, lalu menerjemahkannya ke dalam bahasa Indonesia.

2) Demonstrasi

Dalam fase ini, peserta didik menyanyikan pantun tersebut dalam nuansa daerahnya. Peserta didik bisa saling berbalas pantun antarkelompok. Dengan cara demikian, suasana kelas akan menyenangkan dan melatih peserta didik menunjukkan kreativitasnya dalam menyajikan pantunnya di depan kelas. Dengan demikian, suasana pembelajaran yang aktif, kreatif, dan menyenangkan dapat tercipta.

3) Urun Rembuk

Di sini pendidik membantu para peserta didik berdiskusi mengenai fungsi dan isi pantun sesuai dengan pemahamannya. Setelah berdiskusi, peserta didik melaporkan hasil diskusinya. Dengan melaporkan hasil diskusi di depan kelas, peserta didik ditanamkan rasa percaya diri dan bertanggung jawab. Karakter abad 21 terkait kritis dan komunikatif terlihat pada fase ini. 
4) Kolaborasi

Pada tahap ini, peserta didik saling melengkapi hasil diskusi. Selain itu, peserta didik membandingkan bentuk pantun yang sudah dikenal di Indonesia dengan bentuk pantun yang ada di daerah setempat. Melalui kegiatan ini, peserta didik dilatih untuk inovatif, kerja keras, dan mampu berkontribusi secara sukarela, tanpa paksaan.

5) Refleksi

Pada tahap ini, peserta didik dan pendidik membuat komitmen untuk selalu menggali budaya daerah dan menjadikannya sebagai pedoman hidup. Dengan demikian, peserta didik diajarkan untuk mencintai budaya daerahnya demi memperkuat eksistensi kebudayaan nasional.

\section{SIMPULAN}

Sesuai ulasan tersebut, dapat ditarik simpulan bahwa pantun komunitas masyarakat Desa Kopong berfungsi sebagai sarana hiburan antarkaum muda (rekreatif), sarana penyampaian pesan bernuansa seni dalam bertutur kata, menghasilkan produk lokal seperti kain tenun dengan motif yang indah (estetis), sarana mendidik, mengajar, dan menanamkan nilai-nilai kehidupan (didaktik), sarana penanaman norma yang berlaku di tengah masyarakat terkait perintah dan larangan (moralitas), dan sarana berkomunikasi dengan Tuhan mahapengasih (religius). Isi pantun meliputi penguat nilai ketabahan, keuletan, kesopanan, kesukarelawanan, dan religius. Hasil penelitian memiliki relevansi terhadap pembelajaran Bahasa Indonesia di SMP terisitmwa kompetensi dasar menelaah bentuk dan isi puisi lama Indonesia dengan sintak orientasi, demonstrasi, urun rembuk, kolaborasi, dan refleksi.

\section{DAFTAR PUSTAKA}

Apriansa, D. (n.d.). Studi Identifikasi Jenis-Jenis Pantun dalam Masyarakat Kaur Provinsi Bengkulu. 1(1), 43-50.

Aryanto, S., \& Rakhmat, C. (2014). Analisis Struktur Pantun Karya Siswa Kelas Iv Sdn Nagarawangi 3 Kota Tasikmalaya. PEDADIDAKTIKA: Jurnal Ilmiah Pendidikan Guru Sekolah Dasar, 1(2), 1-11.

Asnawi. (2017). Bahasa Banjar Hulu: pengukuhan warisan tradisi lokal budaya bangsa. 229.

Cohen, L., Manion, L., \& Morrison, K. (n.d.). Research Methods in Education, Sixth Edition.

Eriyanto. (2011). Analisis Isi: Pengantar Metodologi untuk Penelitian Ilmu Komunikasi dan Ilmu-ilmu Sosial Lainnya Kencana (p. ix + 510). http://journal.ui.ac.id/index.php/jkmi/article/viewFile/7832/3899

Hasim, A. (2007). Folklor Indonesia: Ilmu gosip, dongeng, dan lain-lain. Pustaka Utama Grafiti. https://books.google.co.id/books/about/Folklor_Indonesia. $\mathrm{html}$ ?hl=id\&id=dtciAAAAMAAJ\&redir_esc $=\mathrm{y}$

Mahsun. (2007). Metode penelitian bahasa: tahapan strategi, metode dan tekniknya (Revisi). Rajagrafindo Persada. http://digitallib.pps.unj.ac.id/ index.php? $\mathrm{p}=$ show_detail\&id=24322\&keywords $=$

Malaon, T. I. dkk. (1986). Mengengok Tradisi: Sebuah Alternatif bagi Teater Modern. Dewan Kesenian Jakarta Lembaga Studi dan Riset Mahabudhi 
Indonesia.

Martha, E., \& Kresno, S. (2016). Metodologi Penelitian Kualitatif Untuk Bidang Kesehatan (Kasnodihardjo (ed.)). PT Kanisius. https://www.researchgate.net/publication/329763692_PENELITIAN_KUAL ITATIF_DI_BIDANG_KESEHATAN

Miles \& Huberman. (1992). Analisis data kualitatif: Buku sumber tentang metodemetode baru (Tjetjep Rohendi Rohidi (ed.)). UI Press.

Moleong, L. J. (2008). Metodologi penelitian kualitatif (Revisi). PT. Remaja Rosdakarya. http://ailis.lib.unair.ac.id/opac/detail-opac?id=70174

Multafifin. (2015). Kemampuan Menulis Pantun Siswa Kelas VII SMP Negeri 52 Konawe Selatan. Jurnal Humanika, 15, 1-12. https://www.infodesign.org.br/ infodesign/article/view/355\%0Ahttp://www.abergo.org.br/revista/index.php/ ae/article/view/731\%0Ahttp://www.abergo.org.br/revista/index.php/ae/article /view/269\%0Ahttp://www.abergo.org.br/revista/index.php/ae/article/view/10 6

Munir, M. (2020). Nilai-nilai pendidikan karakter dalam sastra lisan pada cerita rakyat abdurrahman ganjur di desa ngroto kecamatan gubug kabupaten grobogan.

Nurhadi, D. (2004). Pembelajaran kontekstual (contextual teaching and learning/CTL) dan penerapannya dalam KBK. Universitas Negeri Malang.

Owon, R. A. S. (2017). PENGEMBANGAN BAHAN AJAR MENULIS Sastra Indonesia di SMP. Jurnal Inovasi Pembelajaran, 3(1), 528-541.

Owon, R. A. S., \& Nanda Saputra. (2021). The Analysis of Function and Poetry Content of Traditional Marriage in Seusina Village Community, Sikka Regency. LingLit Journal Scientific Journal for Linguistics and Literature, 2(1), 17-24. https://doi.org/10.33258/linglit.v2i1.418

Primasari, D., Suyitno, S., \& Rohmadi, M. (2016). Analisis Sosiologi Sastra Dan Nilai Pendidikan Karakter Novel Pulang Karya Leila S. Chudori Serta Relevansinya Sebagai Materi Ajar Apresiasi Sastra Di Sekolah Menengah Atas. Jurnal Penelitian Bahasa, Sastra Indonesia, Dan Pengajarannya, 4(1), $50-64$.

Sari, D. N. (2021). Implementation of Educative Learning Media Counting Tree to Improve Student's Cognitive Abilities in Kartika Tanjung Morawa Kindergarten. Britain International of Linguistics Arts and Education (BIoLAE) Journal, 3(1), 22-28. https://doi.org/10.33258/biolae.v3i1.406

Sartini, N. W. (2009). Menggali Nilai Kearifan Lokal Budaya Jawa Lewat (Bebasan, Saloka, Dan Paribasa). Jurnal Logat, 5(1), 28-37.

Sudaryanto. (1993). Metode dan aneka teknik analisis bahasa: pengantar penelitian wahana kebudayaan secara linguistis. Duta Wacana Universty Press. https://opac.perpusnas.go.id/DetailOpac.aspx?id=196071

Suharsimi Arikunto. (2007). Evaluasi Program Pendidikan: Pedoman Teoritis Praktis Bagi Mahasiswa dan Praktisi Pendidikan. Bumi Aksara.

Widyanti, T. (2016). Penerapan Nilai-Nilai Kearifan Lokal Dalam Budaya Masyarakat Kampung Adat Cireundeu Sebagai Sumber Pembelajaran Ips. $\begin{array}{llll}\text { Jurnal Pendidikan Ilmu Sosial, } & \text { 24(2), }\end{array}$ https://doi.org/10.17509/jpis.v24i2.1452

Wiediharto, V. T., Ruja, I. N., \& Purnomo, A. (2020). Nilai-Nilai Kearifan Lokal Tradisi Suran. Diakronika, 20(1), 13. https://doi.org/10.24036/diakronika/ vol20-iss $1 / 122$ 
Wiguna, M. Z., Yuda, R. K., \& Uli, I. (2017). Analisis Nilai-nilai Pendidikan dalam Pantun Melayu Sambas. Jurnal Pendidikan Bahasa, 6(1), 114-129.

Yuliansyah, A. (2019). Struktur Dan Fungsi Pantun Dalam Upacara Adat Perkawinan Melayu Tanjung Hulu Kecamatan Pontianak Timur. Jurnal Pendidikan Bahasa, 8(2), 281. https://doi.org/10.31571/bahasa.v8i2.1432 